\title{
KORELASI INDEKS MASSA TUBUH DENGAN DERAJAT KEPARAHAN SERANGAN MIGREN TANPA AURA
}

\author{
THE CORRELATION BETWEEN THE BODY MASS INDEX AND THE \\ SEVERITY OF MIGRAINE ATTACK WITHOUT AURA \\ Andry, * Muhammad Akbar, * Hasmawati Basir*
}

\begin{abstract}
Introduction: In Indonesia, there has been only a few studies that correlate Body Mass Index (BMI) to severity of migraine.

Aim: To identify the correlation between the body mass index and the severity of migraine attack without aura.

Methods: The research used the cross sectional design method. The subjects' age was 18 years or above, and they were treated at the neurology outpatient clinic of Dr. Wahidin Sudirohusodo Hospital and its networking hospitals from June through September 2018. The measurement of Body Mass Index (BMI) of the subjects was conducted, and the level of migraine severity was determined using the numeric pain rating scale (NPRS), while the frequency of migraine attacks was determined in 1 month during the last 3 months of the study.

Results: The research results revealed that 45 samples met the inclusion criteria, consisting of $86.7 \%$ women and 13.3\% men. By using Spearman's test, it was found that there was a correlation between the BMI and the pain intensity, and between the BMI and the frequency of the migraine attacks.

Discussion: There were correlations between BMI and pain intensity which confounded by sleep disorder and migraine prophylaxis, and between BMI and the frequency of migraine attacks which confounded by prophylaxis of migraine without aura.
\end{abstract}

Keywords: BMI, migraine rant, obesity, severity

\section{ABSTRAK}

Pendahuluan: Penelitian yang menghubungkan indeks massa tubuh (IMT) dengan derajat keparahan migren masih sedikit di Indonesia.

Tujuan: Mengetahui hubungan IMT dengan derajat keparahan serangan migren tanpa aura.

Metode: Penelitian ini menggunakan metode potong lintang. Subjek berumur 18 tahun atau lebih dan berobat ke Poliklinik Neurologi RSUP Dr. Wahidin Sudirohusodo dan rumah sakit jejaring antara Juni hingga September 2018. Terhadap subjek dilakukan pengukuran IMT. Derajat keparahan migren ditentukan secara kuantitatif melalui penggunaan numeric pain rating scale (NPRS) dan ditentukan frekuensi serangan migren dalam satu bulan pada interval tiga bulan terakhir saat dilakukan penelitian.

Hasil: Didapatkan 45 sampel yang memenuhi kriteria inklusi yang terdiri dari 86,7\% perempuan dan 13,3\% laki-laki. Dengan menggunakan uji Spearman, didapatkan korelasi antara IMT dan tingkat nyeri dan frekuensi serangan migren.

Diskusi: Terdapat korelasi antara IMT, dengan tingkat nyeri yang dirancu dengan gangguan tidur, dan pengobatan preventif, dan antara IMT dengan frekuensi serangan yang dirancu dengan pengobatan preventif pada penderita migren tanpa aura.

Kata kunci: Derajat keparahan, IMT, migren, obesitas

*Bagian Neurologi FK Universitas Hasanuddin, Makassar. Korespondensi: super_andryman@yahoo.com.

\section{PENDAHULUAN}

Epidemi obesitas telah menjadi tantangan masalah kesehatan di seluruh penjuru dunia. Dipicu pertumbuhan ekonomi, industrialisasi, kemajuan transportasi, urbanisasi, gaya hidup sedenter, transisi nutrisi pada makanan olahan, serta asupan makanan tinggi kalori pada 30 tahun terakhir, banyak negara mengalami peningkatan prevalensi obesitas dua hingga empat kali lipat. Obesitas dan berat badan lebih, terjadi pada sepertiga populasi dunia saat ini. ${ }^{1} \quad$ Jika kecenderungan ini terus berlangsung, diperkirakan $38 \%$ populasi dunia akan mengalami berat badan lebih dan 20\% mengalami obesitas di tahun 2030. Pada tahun 1994 prevalensi obesitas di Amerika Serikat 23\%, angka ini meningkat di tahun 2004 menjadi 32\% dan saat ini diperkirakan berkisar 35\%. ${ }^{1}$ Di Amerika Serikat diperkirakan lebih dari $85 \%$ populasi dewasa akan mengalami berat badan lebih atau obesitas pada tahun 2030. Di Cina obesitas terjadi pada hampir separuh $(44,6 \%)$ pada populasi 
berumur di atas 40 tahun. $^{2}$

Pada tahun 2011 WHO menyatakan prevalensi migren pada dewasa di daerah Asia Tenggara 10,9\%. Wanita tercatat lebih banyak menderita migren daripada pria, dengan perbandingan 3:1. Prevalensi migren di negara Asia lainnya seperti Cina 9,3\% (laki-laki $5,9 \%$, perempuan $12,8 \%$ ), ${ }^{2}$ sedangkan di Iran 9,5\%. ${ }^{3}$ Belum ada angka pasti prevalensi migren di Indonesia. Studi yang dilakukan Susilo di RSUP Dr. Wahidin Sudirohusodo, Makassar mengungkapkan dari 530 pasien nyeri kepala yang berobat ke poliklinik selama bulan Januari hingga Desember 2016, 83 (15,6\%) diantaranya didiagnosis sebagai migren. ${ }^{4}$

Beberapa studi menunjukan hubungan yang signifikan antara peningkatan IMT dan insiden migren. ${ }^{5-8}$ Penelitian Vo mengungkapkan wanita yang mengalami peningkatan IMT (obesitas, obesitas berat, dan obesitas mengancam) mengalami peningkatan risiko migren hingga dua kali lipat dibanding kelompok normal. ${ }^{9}$

Pada penderita obesitas terjadi ekspansi jaringan adiposa yang mencetuskan terjadinya inflamasi low grade kronik. Hal ini terjadi karena saat ekspansi jaringan adiposa, banyak sel adiposit mengalami hipoksia yang mencetuskan aktivitas makrofag. Terdapat dua mekanisme yang mendasari, yaitu mekanisme sentral dan mekanisme perifer. Mekanisme sentral ditandai dengan peningkatan sekresi CGRP oleh hipotalamus pada kondisi inflamasi. Pada mekanisme perifer, terjadi ketidakseimbangan adipositokin dimana kadar adiponektin (ADP) menurun dan kadar leptin meningkat. Sifat leptin yang proinflamatori dan ADP yang antiinflamatori menyebabkan inflamasi tetap terus berlangsung dan dipertahankan (kronifikasi). Leptin menghasilkan mediator inflamasi seperti tumor necrosis factor- $\alpha$ (TNF $\alpha$ ) dan interleukin-6 (IL6). Tumor necrosis factor- $\alpha$ memiliki kemampuan menyekresikan CGRP dan bersama IL-6 mencetuskan terjadinya inflamasi neurogenik yang akan terlibat dalam jalur nyeri migren. Kedua mekanisme inilah yang menyebabkan peningkatan intensitas nyeri dan frekuensi pada penderita migren yang disertai peningkatan IMT. ${ }^{10}$

\section{TUJUAN}

Penelitian ini bertujuan untuk mengetahui korelasi indeks massa tubuh (IMT) dengan derajat keparahan serangan migren tanpa aura. Populasi ini dipilih karena semakin meningkatnya prevalensi obesitas dari tahun ke tahun di Indonesia serta morbiditas tinggi yang dialami penderita migren, serta minimnya penelitian sejenis di Indonesia, khususnya di kota Makassar.

\section{METODE}

Penelitian ini merupakan penelitian observasional di RSUP Dr. Wahidin Sudirohusodo, Makassar dan rumah sakit jejaringnya mulai Juni sampai September 2018. Didapatkan sampel berjumlah 45 orang yang memenuhi kriteria inklusi yang terdiri dari 6 orang laki-laki dan 39 orang wanita.

Sampel penelitian adalah penderita dari populasi penelitian yang memenuhi kriteria inklusi yang diperoleh berdasarkan urutan masuknya ke rumah sakit (consecutive sampling). Kriteria inklusi meliputi: penderita yang didiagnosis secara klinis sebagai penderita migren tanpa aura berdasarkan Konsensus Diagnostik dan Penatalaksanaan Nyeri Kepala V Kelompok Studi Nyeri Kepala PERDOSSI 2018, usia 18 tahun atau lebih, dan mengalami migren tanpa aura sekurang-kurangnya satu kali dalam tiga bulan terakhir saat dilakukan penelitian. Kriteria eksklusi meliputi: penderita yang mempunyai kelainan dalam pemeriksaan fisik neurologis, baik berupa defisit neurologis fokal maupun global, penderita dengan gangguan sistemik berupa: hipertensi, diabetes melitus, penyakit infeksi akut dan kronik (artritis reumatoid dan systemic lupus erythematosus/SLE), dan penderita dengan perubahan berat badan lebih atau sama dengan 10\% dalam 3 bulan terakhir saat dilakukan penelitian.

Penderita migren tanpa aura adalah penderita dengan nyeri kepala berulang dengan manifestasi serangan selama 4-72 jam. Karakteristik nyeri kepala unilateral, berdenyut, intensitas sedang atau berat, bertambah berat dengan aktivitas fisik yang rutin dan diikuti dengan nausea dan atau fotofobia dan fonofobia, tanpa disertai aura yang dialami dalam 
1 tahun terakhir.

Indeks massa tubuh (IMT) adalah perbandingan berat badan dalam kilogram dan kuadrat dari tinggi badan dalam meter, yang diukur menggunakan timbangan berat badan digital yang telah dikalibrasi dan stadiometer sesuai prosedur yang telah ditentukan. Derajat keparahan migren adalah tingkat nyeri atau frekuensi saat terjadinya serangan migren, semakin tinggi nilai tingkat nyeri atau frekuensi serangan migren, semakin berat derajat keparahan migren. Tingkat nyeri serangan migren adalah intensitas nyeri saat terjadi serangan migren, ditentukan menggunakan numeric pain rating scale (NPRS) untuk menentukan derajat nyeri rata-rata secara kuantitatif yang dialami selama 3 bulan terakhir, dengan rentang angka 0 hingga 10, hasil ukur berupa angka dimana 0 menunjukan keadaan bebas nyeri dan angka 10 menunjukan nyeri terberat. Frekuensi migren adalah jumlah serangan migren yang terjadi dalam satu bulan selama tiga bulan terakhir.

Data yang terkumpul diolah melalui analisis statistik. Untuk mengetahui korelasi IMT dengan derajat keparahan pada pasien migren digunakan uji korelatif Spearman.

\section{HASIL}

Subjek yang diteliti pada penelitian ini 6 lakilaki dan 39 perempuan. Rerata usia sampel penelitian adalah 40,73 $\pm 13,91$ tahun dengan rentang usia 19-66 tahun. Jumlah sampel umur 18-29 tahun sebanyak 11 orang (24,4\%); umur 30-39 tahun 12 orang (26,7\%); umur 40-49 tahun 7 orang (15,6\%); umur 50-59 tahun 11 orang $(24,4 \%)$; dan umur $60-69$ tahun 4 orang $(8,9 \%)$. Rerata tinggi badan $152,4 \pm 7,38 \mathrm{~cm}$. Rerata berat badan $57,52 \pm 10,22 \mathrm{~kg}$ (Tabel 1).

Dilakukan uji normalitas untuk mengetahui sebaran data pada kelompok IMT, tingkat nyeri, dan frekuensi serangan migren. Diperoleh sebaran data pada kelompok IMT terdistribusi normal $(p=0,20)$, sedangkan sebaran data pada kelompok tingkat nyeri migren dan frekuensi serangan migren tidak terdistribusi normal ( $p=0,02$ dan $p<0,001)$.

Dilakukan uji korelasi Spearman untuk mencari korelasi antara IMT dan tingkat nyeri serangan
Tabel 1. Distribusi Jenis Kelamin dan Kelompok Umur Sampel Penelitian

\begin{tabular}{lc}
\hline \multicolumn{1}{c}{ Karakteristik Demografi } & n (\%) \\
\hline Jenis kelamin & \\
Laki-laki & $6(13,3)$ \\
Perempuan & $39(86,7)$ \\
Umur & \\
$18-29$ & $11(24,4)$ \\
$30-39$ & $12(26,7)$ \\
$40-49$ & $7(15,6)$ \\
$50-59$ & $11(24,4)$ \\
$60-69$ & $4(8,9)$ \\
\hline
\end{tabular}

Pada Tabel 2 dapat dilihat rerata, median serta rentang nilai IMT, PRS dan frekuensi serangan.

Tabel 2. Rerata IMT, Tingkat Nyeri, dan Frekuensi Serangan Penderita Migren Tanpa Aura

\begin{tabular}{lccccc}
\hline $\begin{array}{c}\text { Indikator } \\
\text { yang Diukur }\end{array}$ & Min & Maks & Median & Mean & SD \\
\hline IMT & 17,23 & 33,87 & 24,62 & 24,76 & 4,23 \\
NPRS & 3,00 & 9,00 & 7,00 & 6,64 & 1,69 \\
Frekuensi & 3,00 & 30,00 & 12,00 & 14,13 & 8,61 \\
serangan & & & & & \\
\hline
\end{tabular}

migren (Gambar 1). Secara statistik diperoleh kekuatan korelasi sebesar 0,62 dengan $p<0,001$.

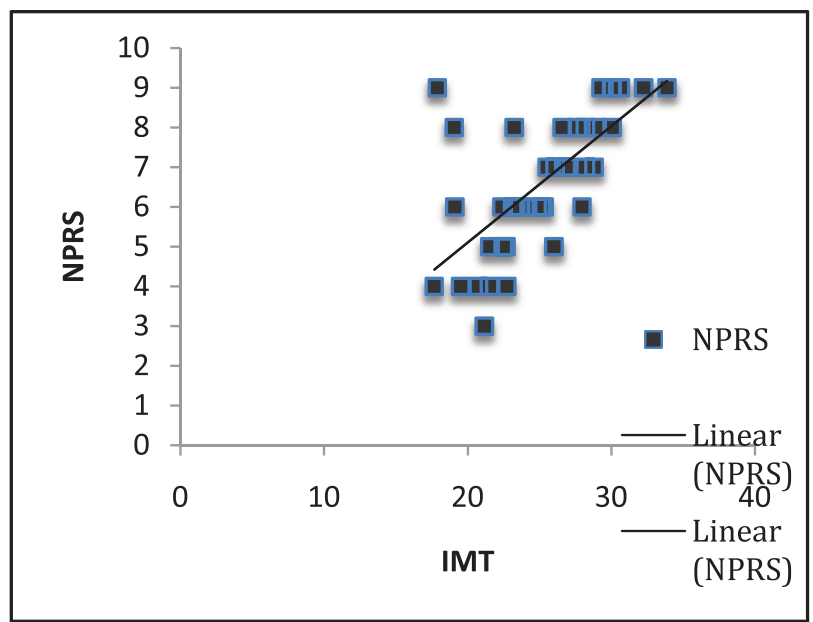

Gambar 1. Hubungan IMT dengan Tingkat Nyeri Serangan pada Penderita Migren Tanpa Aura

Pada uji korelasi Spearman untuk mencari korelasi antara IMT dan frekuensi serangan migren (Gambar 2). Secara statistik diperoleh kekuatan korelasi sebesar 0,58 dengan $\mathrm{p}<0,001$.

Pada penelitian ini terdapat beberapa faktor lain yang dapat memengaruhi derajat keparahan 


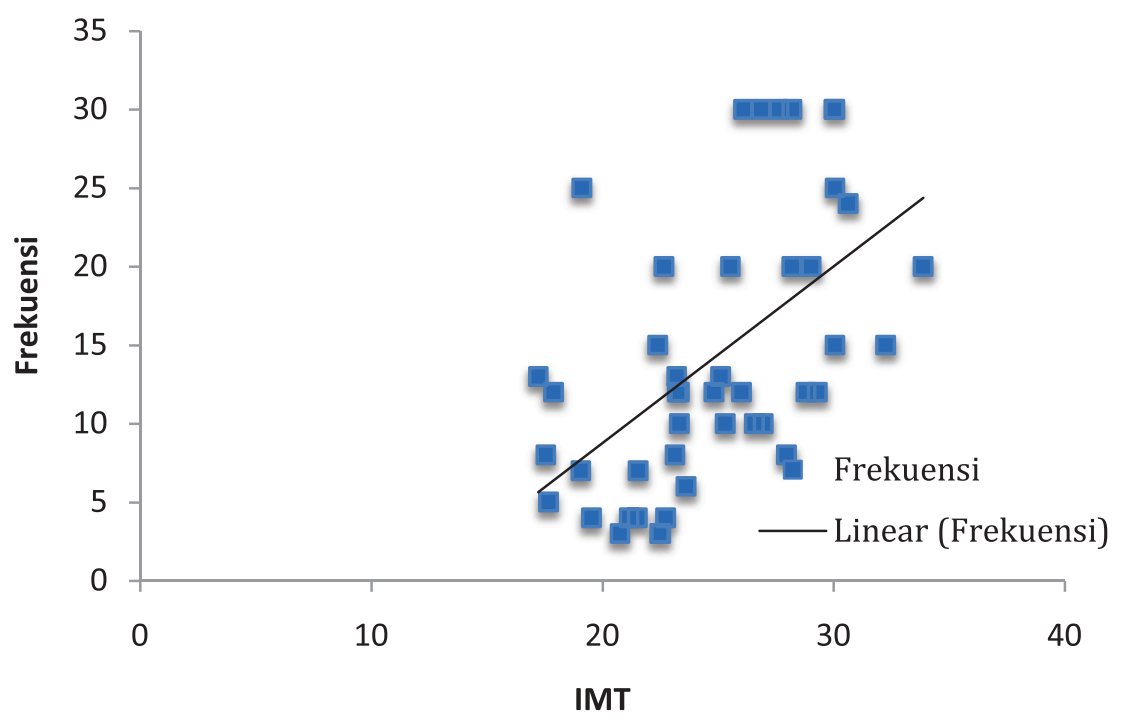

Gambar 2. Hubungan IMT dengan Frekuensi Serangan pada Penderita Migren Tanpa Aura

migren yaitu: gangguan tidur, gangguan psikiatri, faktor hormonal, makanan, dan riwayat pengobatan preventif. Pada 45 subjek ini, didapatkan 11 orang $(24,4 \%)$ memiliki satu macam faktor lain yang dapat memengaruhi migren, 9 orang (20\%) memiliki 2 faktor, dan 1 orang $(2,2 \%)$ memiliki 3 faktor. Tujuh orang $(15,6 \%)$ memiliki gangguan tidur berupa insomnia $(100 \%)$. Empat orang $(8,9 \%)$ memiliki kebiasaan makanan berupa: coklat 1 orang $(25 \%)$; penggunaan monosodium glutamate (MSG) 1 orang (25\%); dan mi instan 2 orang (50\%). Sebelas orang $(24,4 \%)$ memiliki faktor psikiatrik berupa gangguan stres akut (100\%) dengan stresor yang meliputi: penyakit migren yang diderita 4 orang (36,3\%), tugas/pekerjaan 4 orang $(36,3 \%)$, penyakit lain 1 orang $(9,1 \%)$, baru melahirkan 1 orang $(9,1 \%)$, dan kematian anggota keluarga $(9,1 \%)$. Empat orang $(8,9 \%)$ memiliki faktor hormonal berupa menstruasi $(100 \%)$. Enam orang $(13,3 \%)$ menjalani pengobatan preventif migren saat dilakukan penelitian ini, 4 orang $(66,7 \%)$ menggunakan asam valproat, dan 2 orang (33,3\%) menggunakan propanolol (Tabel 3).

Tabel 3. Uji Hubungan antara Faktor-faktor Lain dengan Tingkat Nyeri Migren

\begin{tabular}{lc}
\hline \multicolumn{1}{c}{ Faktor Perancu } & Tingkat Nyeri \\
\hline Gangguan tidur $(\mathrm{n}=7)$ & $\mathrm{p}=0,004$ \\
Makanan $(\mathrm{n}=4)$ & $\mathrm{p}=0,598$ \\
Gangguan psikiatri $(\mathrm{n}=11)$ & $\mathrm{p}=0,070$ \\
Faktor hormonal $(\mathrm{n}=4)$ & $\mathrm{p}=0,093$ \\
Pengobatan preventif $(\mathrm{n}=6)$ & $\mathrm{p}=0,001$ \\
\hline
\end{tabular}

Pada analisa statistik menggunakan uji MannWhitney ditemukan gangguan tidur dan pengobatan preventif berhubungan bermakna dengan derajat nyeri migren (Tabel 3); serta didapatkan pengobatan preventif berhubungan bermakna dengan frekuensi serangan migren (Tabel 4).

Tabel 4. Uji Hubungan antara Faktor-faktor Perancu dengan Frekuensi Serangan Migren

\begin{tabular}{lc}
\hline \multicolumn{1}{c}{ Faktor Perancu } & Frekuensi \\
\hline Gangguan tidur $(\mathrm{n}=7)$ & $\mathrm{p}=0,068$ \\
Makanan $(\mathrm{n}=4)$ & $\mathrm{p}=0,733$ \\
Gangguan psikiatri $(\mathrm{n}=11)$ & $\mathrm{p}=0,056$ \\
Faktor hormonal $(\mathrm{n}=4)$ & $\mathrm{p}=0,307$ \\
Pengobatan preventif $(\mathrm{n}=6)$ & $\mathrm{p}=0,005$ \\
\hline
\end{tabular}

\section{PEMBAHASAN}

Pada penelitian ini, dari sampel yang berjumlah 45 orang, didapatkan angka kejadian migren pada wanita sebesar $86,7 \%$, enam kali lipat lebih rentan dibanding laki-laki. Angka ini tidak dapat mewakili populasi karena cara pengambilan sampel secara consecutive sampling.

Penelitian ini menunjukan korelasi positif antara IMT dengan derajat keparahan serangan pada penderita migren tanpa aura. Semakin tinggi nilai IMT, semakin tinggi nilai tingkat nyeri dan frekuensi serangan migren. Hal ini serupa dengan yang ditemukan Ornello dkk, yang menemukan peningkatan frekuensi migren seiring dengan peningkatan IMT. $^{6}$ Temuan ini diperkuat oleh penelitian Farello yang menemukan bahwa terjadi 
peningkatan frekuensi dan tingkat nyeri pada anak penderita migren dengan obesitas dibanding kontrol. ${ }^{11}$ Kedua studi ini mengemukakan peran CGRP dan sitokin-sitokin proinflamasi (IL-6 dan TNF $\alpha$ ) yang kadarnya meningkat seiring dengan penumpukan lemak yang terjadi pada peningkatan berat badan.

Pencetus nyeri pada migren multifaktorial. ${ }^{12}$ Pada penelitian ini secara statistik ditemukan gangguan tidur dan riwayat pengobatan preventif menjadi perancu pada tingkat nyeri serangan migren, sedangkan riwayat pengobatan preventif menjadi perancu pada frekuensi serangan migren.

Gangguan tidur yang ditemukan pada penelitian ini berupa insomnia. Insomnia merupakan gangguan tidur dimana penderita mengeluh kesulitan untuk memulai tidur atau mempertahankan tidurnya meskipun terdapat kesempatan untuk tidur, dikondisikan untuk tidur, dan punya waktu untuk tidur. Pada pasien insomnia tidurnya menjadi singkat dan kurang adekuat, mudah terganggu, kualitas buruk, tidak merasa segar waktu bangun tidur, tidak nyaman, atau tidak menimbulkan restorasi. Lama tidur kurang dari 6 jam, dan keluhan tersebut terjadi minimal 3 hari dalam satu minggu. ${ }^{13}$ Pada penelitian ini terdapat hubungan antara insomnia dengan tingkat nyeri migren. Hal ini sesuai dengan temuan Degard yang mengemukakan penderita insomnia memiliki risiko 1,5-1,7 kali menderita migren dibanding kelompok kontrol. ${ }^{14}$ Hubungan insomnia dengan migren terletak pada siklus kadar katekolamin dan glukokortikoid yang dihasilkan secara endogen saat beraktivitas. Hal ini didukung oleh temuan peningkatan kadar katekolamin pada penderita migren dengan serangan saat bangun pagi hari. Kadar katekolamin yang meningkat akan meningkatkan kadar norepinefrin yang dapat mengaktifkan nosiseptor di pons dan batang otak. Reseptor di pons dan batang otak selain berhubungan dengan nyeri juga berbagi fungsi mengatur siklus tidur. Reseptor ini memiliki sinaps dengan trigeminal nucleus caudatus (TNC) melalui nukleus traktus salitarius dan nukleus parabrakialis. Aktivasi TNC dapat turut mengaktifkan kompleks trigeminoservikal (trigeminocervical complex, TCC) yang mencetuskan serangan migren. ${ }^{15}$
Pengobatan preventif pada migren adalah usaha untuk mengurangi frekuensi dan tingkat nyeri pada penderita migren. Indikasi pemberian pengobatan preventif antara lain: serangan berulang lebih dari 2 kali perminggu yang mengganggu aktivitas meskipun telah diberikan pengobatan akut yang adekuat; nyeri kepala migren yang berlangsung lebih dari 48 jam; pengobatan akut tidak efektif; terdapat kontraindikasi/ efek samping obat; dan keinginan atau permintaan pasien sendiri. Pada penelitian ini terdapat 6 orang $(13,3 \%)$ yang menjalani pengobatan preventif, 4 orang $(66,7 \%)$ menggunakan asam valproat, dan 2 orang $(33,3 \%)$ menggunakan propanolol. Perhitungan secara statistik menggunakan uji MannWhitney menunjukan adanya hubungan antara pengobatan preventif dengan tingkat nyeri $(\mathrm{p}=0,001)$ dan frekuensi serangan $(p=0,005)$.

Kelebihan penelitian ini terletak pada keberadaannya yang merupakan studi pertama sejenis di Makassar dan diharapkan dapat menjadi pijakan untuk studi lebih lanjut.

Keterbatasan dalam penelitian ini adalah pengukuran IMT pada individu sehat yang muskular akan mengaburkan hasil karena kandungan lemak tubuh rendah tapi dapat diklasifikasikan menjadi berat badan lebih ataupun obesitas. Data intensitas nyeri dan frekuensi serangan migren mengandalkan metode self-reported yang berpotensial menimbulkan recall bias. Desain penelitian yang potong lintang menyebabkan tidak semua faktor lain yang memengaruhi migren dapat dikontrol.

\section{KESIMPULAN}

Sebagai kesimpulan, terdapat korelasi antara IMT dengan derajat nyeri migren. Namun derajat nyeri migren juga berhubungan bermakna dengan gangguan tidur dan pengobatan preventif migren. Terdapat korelasi antara IMT dengan frekuensi serangan migren; namun pengobatan preventif migren juga berhubungan bermakna dengan frekuensi serangan migren tanpa aura.

\section{DAFTAR PUSTAKA}

1. Hruby A, Hu FB. The epidemiology of obesity: a big picture. Pharmacoeconomics. 2015;33(7):673-89.

2. Yu S, Liu R, Yang X, Zhao G, Qiao X, Feng J, dkk. 
BMI and migrain: a survey of the chinese adult population. J Headache Pain. 2012;13:531-6.

3. Sadeghi O, Askari G, Maghsoudi Z, Ghiasyand R, Khorvash F. The association between abdominal obesity and characterictic migren in iranian. Iran J Nurs Midwifery Res. 2016;21(3):271-7.

4. Susilo, Goysal Y, Basir H. The prevalence of headache among patients in neurology outpatient clinic Wahidin Sudirohusoda hospital from January to December 2016. National Scientific Meeting Perdossi; 2017.

5. Ford ES, Li C, Pearson WS, Zhao G, Strine TW, Mokdad AH. Body mass index and headaches: findings from a national sample of US adults. Cephalalgia. 2008;28:1140-6.

6. Ornello R, Ripa P, Pistoia F, Degan D, Tiseo C, Carolei A, Sacco S. Migraine and body mass index categories: a systematic review and meta analysis of observational studies. J Headache Pain Mar. 2015;16(1):27.

7. Peterlin, BL, Sacco S, Bernecker C, Scher AI. Adipokines and migraine: a systematic review. Headache. 2016;56(4):622-44.

8. Robberstad L, Dyb G, Hagen K, Stovner LJ, Holmen TL, Zwart JA. An unfavorable lifestyle and recurrent headaches among adolescents: the HUNT study. Neurology. 2010;75(8):712-7.

9. Vo M, Ainalem A, Qiu C, Peterlin BL, Aurora SK, Williams MA. Body mass index and adult weight gain among reproductive age women with migraine. Headache. 2011;51(4):559.

10. Aminoff MJ, Boller F, Swaab DF, penyunting. Handbook of clinical neurology. Volume Ke-93. Seri Ke-3. Edinburgh: Elsevier; 2011.

11. Farello G, Ferrera P, Antenucci A, Basti C, Verroti A. The link between obestity and migraine in childhood: a systematic review. Ital J Pediatr. 2017;43:27.

12. Moskowitz MA, Dalkara T, penyunting. Neurobiological basis of migraine. New York: Wiley Blackwell; 2017. h. 3-29.

13. Purnomo $\mathrm{H}$, Islamiyah WR. Paduan tata laksana gangguan tidur. Surabaya: Kelompok Studi Gangguan Tidur Perdossi; 2014. h. 21.

14. Degard SS, Engstrom M, Sand T, Stovner LJ, Zwart JA, Hagen K. Associations between sleep disturbance and primary headaches: the third Nord-Trondelag Health Study. J Headache Pain. 2010;11(3):197-206.

15. Brennan KC, Charles A. Sleep and headache. HHS Public Access. 2009;29(4):406-18. 